\title{
Demographic characteristics and cost of treatment among oncology patients in a publicly funded system, the Ontario Trillium Drug Program: a retrospective cohort study
}

\author{
Stephanie Y. Cheng MSc, Farah E. Saxena MPH, Soo Jin Seung BSc, Craig C. Earle MD, \\ Kelvin Chan MD, Nicole Mittmann MSc PhD
}

\section{Abstract}

Background: The aim of this study was to characterize the demographic characteristics and investigate the cost of a publicly funded system, the Ontario Trillium Drug Program (TDP), for an oncology patient population.

Methods: We ascertained all TDP claims between April 1997 and December 2016 from the Ontario Drug Benefit database to assess use and cost. Each drug was classified as a cancer treatment drug, cancer supportive therapy drug or noncancer drug. We also identified a cohort of patients with cancer with least 1 TDP claim, for whom we examined demographic and claims-related characteristics.

Results: Over the study period, 50975293 TDP claims totalling $\$ 4.8$ billion were made. Although the proportion of cancer claims among all TDP claims remained constant between 1997 and 2016, the total annual cost of cancer treatment drugs increased nearly 40-fold. Imatinib and lenalidomide together accounted for nearly half of the cost of all cancer treatment drugs. We identified a cohort of 49892 patients with cancer, of whom 18631 (37.3\%) were enrolled in the TDP before their cancer diagnosis and 31261 (62.7\%) were enrolled after their diagnosis. The former were more likely than the latter to be in lower income quintiles and to have more chronic conditions. Significant differences were also found in the distribution of cancer diagnoses between the 2 groups.

Interpretation: In the TDP, use increased over time and differed across cancer diagnoses and drugs. These results have public health and policy implications as antineoplastic drug costs continue to rise and place a burden on patients.

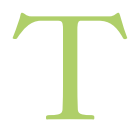
he Ontario Drug Benefit (ODB) is a Ministry of Health and Long-Term Care program covering about $28 \%$ of the Ontario population. It pays for over 4400 prescription drug products, typically orally administered medications, for which patients would normally have to pay for out of pocket. ${ }^{1-3}$ Drugs administered in hospital, such as intravenously given chemotherapy medications, are covered by other provincial drug reimbursement programs (such as the New Drug Funding Program) or the hospital's global budget and are therefore out of scope for the ODB. All eligible Ontario residents qualify for the ODB upon their 65th birthday; however, residents less than age 65 can apply to the Trillium Drug Program (TDP). This program funds prescription drugs that are approved and listed on the ODB formulary, for which patients would otherwise have to pay out of pocket, and patients must spend more than about $4 \%$ of the net household income on prescription drugs to be eligible. ${ }^{1,2}$ When enrolled in the TDP, the patient is required to pay only an annual deductible (about $4 \%$ of the household income after taxes) before the TDP coverage can begin, after which the patient is required to pay only up to $\$ 2$ for each prescription that is filled or refilled. ${ }^{4}$ The number of TDP recipients tripled between 2000 and 2016, and in 20162017, over 150500 households (median household income $\$ 27600$ ) were enrolled in the program..$^{5,6}$ In the same period, the TDP expenditure was nearly $\$ 500$ million, and

Competing interests: Nicole Mittmann was employed by Cancer Care Ontario until May 2019 during the course of this analysis. Craig Earle is employed by the Canadian Partnership Against Cancer. Kelvin Chan is a consultant of Cancer Care Ontario. Soo Jin Seung consults with the pharmaceutical industry via the Health Outcomes and PharmacoEconomics (HOPE) Research Centre. No other competing interests were declared.

This article has been peer reviewed.

Correspondence to: Nicole Mittmann, nicole.mittmann@sunnybrook.ca CMAJ Open 2019. DOI:10.9778/cmajo.20190011 
the program was used by about $5 \%$ of all ODB recipients taking a publicly funded cancer drug. ${ }^{\text {? }}$

Since 2004, the cost of cancer drugs has risen at a rate 5 times greater than the increase in cancer incidence and far beyond the rate of inflation. ${ }^{8,9}$ This rise has been primarily due to the introduction of high-cost biologic drugs and targeted therapies, as well as an increase in patients receiving adjuvant therapy and home care. ${ }^{10}$ The high cost of cancer treatment is associated with considerable distress and worse outcomes, which has led to the concept of "financial toxicity." has shown that financial toxicity is related to poorer healthrelated quality of life and decreased improvement in the 2 years after a cancer diagnosis. ${ }^{11}$ In 2011, Canadian households spent an average of nearly $\$ 500$ on out-of-pocket prescription drugs; the amount was substantially higher among older adults. ${ }^{12-14}$ Furthermore, the authors of a 2018 study estimated that 731000 Canadians had to borrow money to pay for prescriptions in the previous year. ${ }^{15}$ There is also evidence that patients may decide against taking their cancer medications or reduce dosages because of high costs. ${ }^{12,16,17}$ Moreover, specialty drugs are becoming increasingly common, accounting for more than $25 \%$ of total drug costs in 2014, and with a cost per claim 25 times greater than that of traditional drugs. ${ }^{18,19}$ Cancer drugs, cholesterol-lowering drugs and immunosuppressant drugs combined accounted for about $33 \%$ of the overall growth in drug spending in Canada between 2005 and 2010, with trends suggesting that they will continue to drive drug spending in the coming years. ${ }^{20}$ The TDP is becoming increasingly important for residents who rely on the support of the publicly funded system for their drug expenditures.

There is little information on use of health care resources, demographic characteristics and costs of a financial assistance program such as the TDP. The objective of the current study was to describe the use of the TDP as a whole and, more specifically, one of the cost drivers: oncology treatment. We also wished to determine the demographic characteristics and cancer drug costs among people with a cancer diagnosis covered under the TDP.

\section{Methods}

\section{Data sources}

The ODB database contains information on claims for prescription drugs covered under the ODB program, including those claimed through the TDP, for those aged 65 or more, and those receiving social assistance. The information includes the program through which the drug is funded (used to identify a TDP claim), service date, Drug Information Number and total amount paid (by ODB). We used the Ontario Cancer Registry to identify incident cancer cases in Ontario. We obtained patient demographic characteristics, such as age, sex, income quintile and rural residence, from the Registered Persons Database. We used the Johns Hopkins Adjusted Clinical Group System Resource Utilization Bands to describe predicted resource use: $0=$ no use or invalid diagnosis, $1=$ healthy user, $2=$ low user, $3=$ moderate user, $4=$ high user, and $5=$ very high user. ${ }^{21}$
We used previously validated algorithms to identify patients with the following chronic conditions: asthma, ${ }^{22}$ congestive heart failure, ${ }^{23}$ hypertension, ${ }^{24}$ diabetes,${ }^{25}$ rheumatoid arthritis, ${ }^{26}$ and Crohn disease and colitis. ${ }^{27}$ These algorithms were validated based on administrative databases, such as the Discharge Abstract Database for inpatient hospital discharges from acute, rehabilitation, chronic and day surgery institutions in Ontario, the Same Day Surgery Database for ambulatory surgery in day surgery institutions, the National Ambulatory Care Reporting System for visits to hospital and communitybased ambulatory care, and the Ontario Health Insurance Plan for physician billing and diagnosis information, including codes for services provided, date of service and associated diagnoses, as well as fee paid. Further information on the validations of each chronic condition can be found elsewhere. ${ }^{22-27}$

All data sets were linked by means of unique encoded identifiers and analyzed at ICES. Unique encoded identifiers for each patient were linked across the health administrative databases listed above to aggregate and analyze his or her health care data for the purposes of our study.

\section{Study design}

We identified all TDP claims between Apr. 1, 1997, and Dec. 31, 2016. Using the Drug Information Number, available in the TDP data, we classified each drug claim as a cancer treatment, cancer supportive therapy or other. We identified cancer treatment drugs using the ODB therapeutic classification of "antineoplastic agents." Cancer supportive therapy drugs were identified through the Drug Information Number. Cancer treatment medications were further grouped as cytotoxic chemotherapy, luteinizing hormone-releasing hormone agonist, aromatase inhibitor, antiandrogen or a specific antineoplastic treatment drug (e.g., tamoxifen, imatinib, capecitabine). All drugs were verified and cancer treatment medications were categorized by an independent oncology pharmacist. Further details on drug classification can be found in Supplementary Table S1, Appendix 1 (available at www. cmajopen.ca/content/7/3/E516/suppl/DC1). Lacking information on indication, we categorized somatostatins as supportive therapy (even though they can be used to treat some malignant disorders) to remain conservative in estimating treatment costs. We examined the year-over-year changes in distribution of the number of TDP drug claims, the average paid per claim (defined as the total paid by the TDP divided by the number of TDP claims) and costs across drug groups. All costs were inflated to 2016 with the use of the Consumer Price Index. ${ }^{28}$

From the TDP data, we identified a retrospective cohort of patients in whom an index (first) primary cancer was diagnosed between Apr. 1, 1997, and Dec. 31, 2016 using the Ontario Cancer Registry. We excluded non-Ontario residents, patients in whom cancer was diagnosed before age 18 years (owing to the incomplete capture of pediatric patients in the Ontario Cancer Registry) or after age 64 years (owing to eligibility for the ODB Seniors program) and patients who died before cancer diagnosis. To examine how baseline characteristics of patients who were enrolled in the TDP before or after a cancer diagnosis may differ, we classified each patient 
as having been enrolled in the TDP before or after their index cancer diagnosis based on the timing of their first TDP claim. All patient groups developed in this study were identified a priori. Demographic variables including age, sex, average neighbourhood income quintile, rural residence and comorbidities were examined at cancer diagnosis.

\section{Statistical analysis}

We described patients' baseline demographics and cancer characteristics using descriptive statistics (mean and standard deviation, median and interquartile range for continuous variables, and proportions for categorical variables). Patients with missing or unknown demographic information were reported as such, and values were not imputed. We assessed differences between groups using $\chi^{2}$ tests and $t$ tests. We performed statistical analyses using SAS Enterprise Guide version 6.1 (SAS Institute).

\section{Ethics approval}

The use of data in this project was authorized under section 45 of Ontario's Personal Health Information Protection Act, which does not require review by a research ethics board.

\section{Results}

In the 20-year study period, 50975293 claims by all patients to the TDP were identified, with a total value of $\$ 4796757334$.
Figure 1 illustrates the trend over time for the total number of TDP claims and the average paid per claim from 1997 to 2016. In the first year that TDP data became available (1997), there were 312276 claims to the TDP, of which 1719 (0.6\%) were for cancer treatment drugs. Although the proportion of cancerrelated claims relative to all TDP claims remained constant, the total annual cost of cancer treatment drugs increased, from \$1 062641 (4.3\% of total TDP cost) in 1997 to $\$ 40.1$ million (7.9\% of total TDP cost) in 2016, a nearly 40-fold increase (Figure 2), and the average amount paid per claim increased from $\$ 618$ to $\$ 2106$ over the same period. Different treatment drugs dominated total annual TDP costs throughout the study period: interferon accounted for the highest proportion of the annual total (upward of 60\%) from 1997 to 2002, after which dominance shifted to imatinib, and, finally, dasatinib and lenalidomide accounted for about $40 \%$ of the annual total from 2014 to 2016. More details on year-over-year costs for selected high-cost cancer treatment drugs can be found in Supplementary Figure S1, Appendix 1.

We retrospectively identified 81020 patients with cancer among the TDP claimants over the study period, of whom 31128 (38.4\%) were excluded: living outside Ontario (3567), age less than 18 years at diagnosis (603), age 65 years or more at diagnosis (21 076) and death date before diagnosis date or cancer diagnosis before Apr. 1, 1997 (5882). Of the remaining 49892 patients, $31261(62.7 \%)$ had their first TDP claim

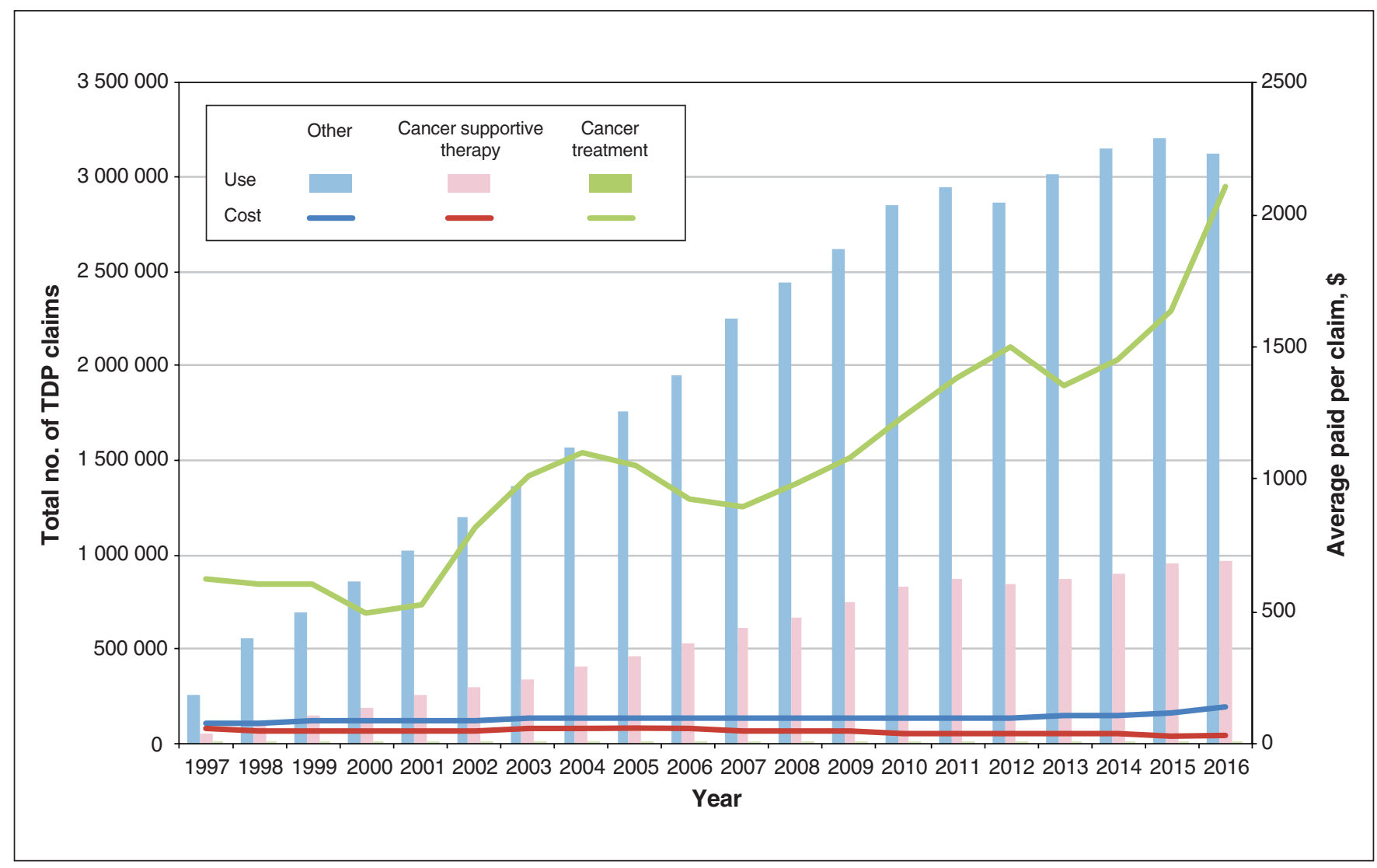

Figure 1: Total number of Trillium Drug Program (TDP) claims and average paid per claim, by drug group, Apr. 1, 1997, to Dec. 31, 2016, adjusted for inflation to 2016. The number of claims for cancer treatment drugs was sufficiently low so as to not display graphically. 


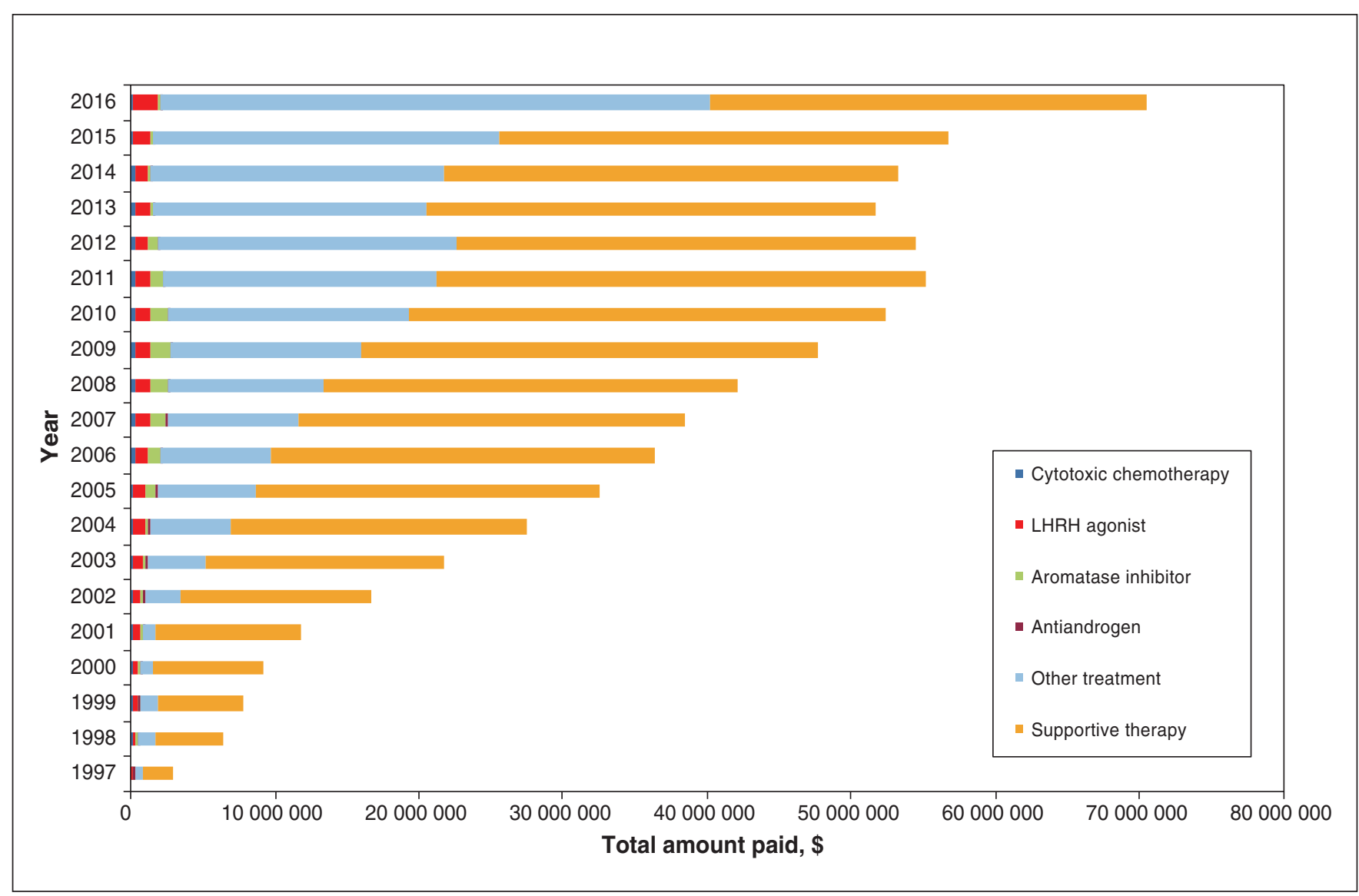

Figure 2: Total amount paid for Trillium Drug Program cancer treatment and supportive therapy drugs, adjusted for inflation to 2016. Note: $\mathrm{LHRH}=$ luteinizing hormone-releasing hormone.

after their cancer diagnosis, and $18631(37.3 \%)$ had their first TDP claim before their cancer diagnosis. Compared to those who had their first TDP claim after their cancer diagnosis, those who had their first TDP claim before their cancer diagnosis were significantly older (median age $59 \mathrm{yr} v .54 \mathrm{yr}$ ), and a higher proportion were male ( $44.2 \%$ v. $40.6 \%)$, had lower income (50.4\% v. $43.2 \%$ in the 2 lowest quintiles) and lived in rural areas $(18.7 \%$ v. $14.0 \%)$ (Table 1$)$. They also had significantly higher resource use (as determined by their Adjusted Clinical Group Resource Utilization Bands) and more chronic conditions at cancer diagnosis. In the 12 months before cancer diagnosis, patients' TDP claims were fairly stable, no matter the eventual cancer diagnosis, averaging \$300-\$400 per month (data not shown). However, there was a significant increase in the average TDP monthly claims in the first month after cancer diagnosis compared to the month before diagnosis for patients with brain cancer (> 500\%), leukemia (> 70\%), prostate cancer (>30\%) and myeloma (nearly 30\%) (data not shown).

The distribution of cancer diagnoses also varied significantly between the 2 patient groups. Of those who were enrolled in the TDP before receiving their cancer diagnosis, 2874 (15.4\%) had breast cancer and 2490 (13.4\%), lung cancer (Figure 3). Among those who were enrolled in the TDP after their cancer diagnosis, a much larger proportion $(8565$
[27.4\%]) had breast cancer, and 2896 (9.3\%) had prostate cancer, 2160 (6.9\%) had colorectal cancer, 1958 (6.3\%) had lymphoma and 1810 (5.8\%) had lung cancer.

\section{Interpretation}

This retrospective cohort study showed that the majority of all TDP claims between 1997 and 2016 were for drugs unrelated to cancer treatment or supportive therapy; however, the total annual cost of TDP claims increased significantly over the study period, far outpacing the increase in the number of claims. The average amount paid per claim was highest for cancer treatment drugs. Among cancer treatment drugs, the introduction of immunotherapies greatly contributed to the rising TDP cost to fund cancer treatment over the observation period. Those who were enrolled in the TDP before their cancer diagnosis had more comorbidities than those who were enrolled in the program after their cancer diagnosis, and breast cancer accounted for the highest proportion of cancer cases among those who were enrolled in the TDP after their cancer diagnosis.

We found that both the total and average amount paid per claim for cancer treatment drugs increased significantly between 1997 and 2016 compared to noncancer and supportive drugs. These results are consistent with the literature, 


\begin{tabular}{|c|c|c|c|c|}
\hline \multirow[b]{2}{*}{ Characteristic } & \multicolumn{3}{|c|}{ No. $(\%)$ of patients* } & \multirow[b]{2}{*}{$\begin{array}{l}\text { Standardized } \\
\text { difference }\end{array}$} \\
\hline & $\begin{array}{c}\text { TDP claims } \\
\text { began before } \\
\text { cancer diagnosis } \\
n=18631\end{array}$ & $\begin{array}{c}\text { TDP claims } \\
\text { began after } \\
\text { cancer } \\
\text { diagnosis } \\
n=31261\end{array}$ & $\begin{array}{c}\text { Overall } \\
n=49892\end{array}$ & \\
\hline Age at diagnosis date, $y r$, mean $\pm S D$ & $56.23 \pm 8.14$ & $51.33 \pm 9.73$ & $53.16 \pm 9.47$ & 0.55 \\
\hline Age at diagnosis date, yr, median (IQR) & $59(53-62)$ & $54(46-59)$ & $56(49-60)$ & 0.63 \\
\hline \multicolumn{5}{|l|}{ Age group at cancer diagnosis, yr } \\
\hline $18-24$ & $134(0.7)$ & $636(2.0)$ & $770(1.5)$ & 0.11 \\
\hline $25-44$ & $1572(8.4)$ & $5858(18.7)$ & $7430(14.9)$ & 0.30 \\
\hline $45-64$ & $16925(90.8)$ & 24767 (79.2) & $41692(83.6)$ & 0.33 \\
\hline \multicolumn{5}{|l|}{ Sex } \\
\hline Female & $10387(55.8)$ & $18559(59.4)$ & $28946(58.0)$ & 0.07 \\
\hline Male & $8244(44.2)$ & $12702(40.6)$ & $20946(42.0)$ & 0.07 \\
\hline \multicolumn{5}{|l|}{ Income quintile } \\
\hline 1 (lowest) & $5009(26.9)$ & $6713(21.5)$ & $11722(23.5)$ & 0.13 \\
\hline 2 & $4385(23.5)$ & $6798(21.7)$ & $11183(22.4)$ & 0.04 \\
\hline 3 & $3656(19.6)$ & $6253(20.0)$ & 9909 (19.9) & 0.01 \\
\hline 4 & $3144(16.9)$ & $6030(19.3)$ & $9174(18.4)$ & 0.06 \\
\hline 5 (highest) & $2379(12.8)$ & $5381(17.2)$ & $7760(15.6)$ & 0.12 \\
\hline Unknown/missing & $58(0.3)$ & $86(0.3)$ & $144(0.3)$ & 0.01 \\
\hline \multicolumn{5}{|l|}{ Residence } \\
\hline Urban & $15138(81.2)$ & 26853 (85.9) & 41991 (84.2) & 0.13 \\
\hline Rural & $3490(18.7)$ & $4393(14.0)$ & $7883(15.8)$ & 0.13 \\
\hline Unknown/missing & $\leq 5$ & $\leq 20$ & $\leq 20$ & 0.02 \\
\hline \multicolumn{5}{|l|}{ Chronic conditions } \\
\hline Asthma & $3269(17.5)$ & $3349(10.7)$ & $6618(13.3)$ & 0.20 \\
\hline Congestive heart failure & $1383(7.4)$ & $476(1.5)$ & $1859(3.7)$ & 0.29 \\
\hline $\begin{array}{l}\text { Chronic obstructive pulmonary } \\
\text { disease }\end{array}$ & $4336(23.3)$ & $3215(10.3)$ & $7551(15.1)$ & 0.35 \\
\hline Hypertension & $10583(56.8)$ & $9925(31.7)$ & $20508(41.1)$ & 0.52 \\
\hline Diabetes & $6356(34.1)$ & $4512(14.4)$ & $10868(21.8)$ & 0.47 \\
\hline Rheumatoid arthritis & $641(3.4)$ & $397(1.3)$ & $1038(2.1)$ & 0.14 \\
\hline Crohn disease and colitis & $441(2.4)$ & $288(0.9)$ & 729 (1.5) & 0.11 \\
\hline
\end{tabular}

which shows an increasing burden of high-cost biologic drugs among people enrolled in the $\mathrm{TDP}^{6}$ and a substantial overall economic burden of cancer care in Canada. ${ }^{29}$ In 2016, the global cost of cancer treatment drugs increased by nearly $15 \%$ (about US $\$ 90$ billion), and these drugs were found to be one of the fastest-growing components in pharmaceutical spending. ${ }^{20,30}$

The increase in oncology-related costs and number of TDP claims over time can be attributed to the uptake of newer therapies. This was not offset by the use of generic medications, as with increasing number of patients receiving treatment and increasing length of treatment duration, older brands are used more often. ${ }^{20,30,31}$ This is further evidenced by our finding that the year-over-year increase in expenditure was closely mirrored by the introduction and approval of new oral treatment drugs, such as imatinib in 2001, dasatinib in 2008 and lenalidomide in 2009, some of the most expensive cancer drugs on the market. ${ }^{32}$ The availability of generic imatinib, in 2013, was reflected in a slight decline in total TDP costs, which was not sustained, as claims for abiraterone, 


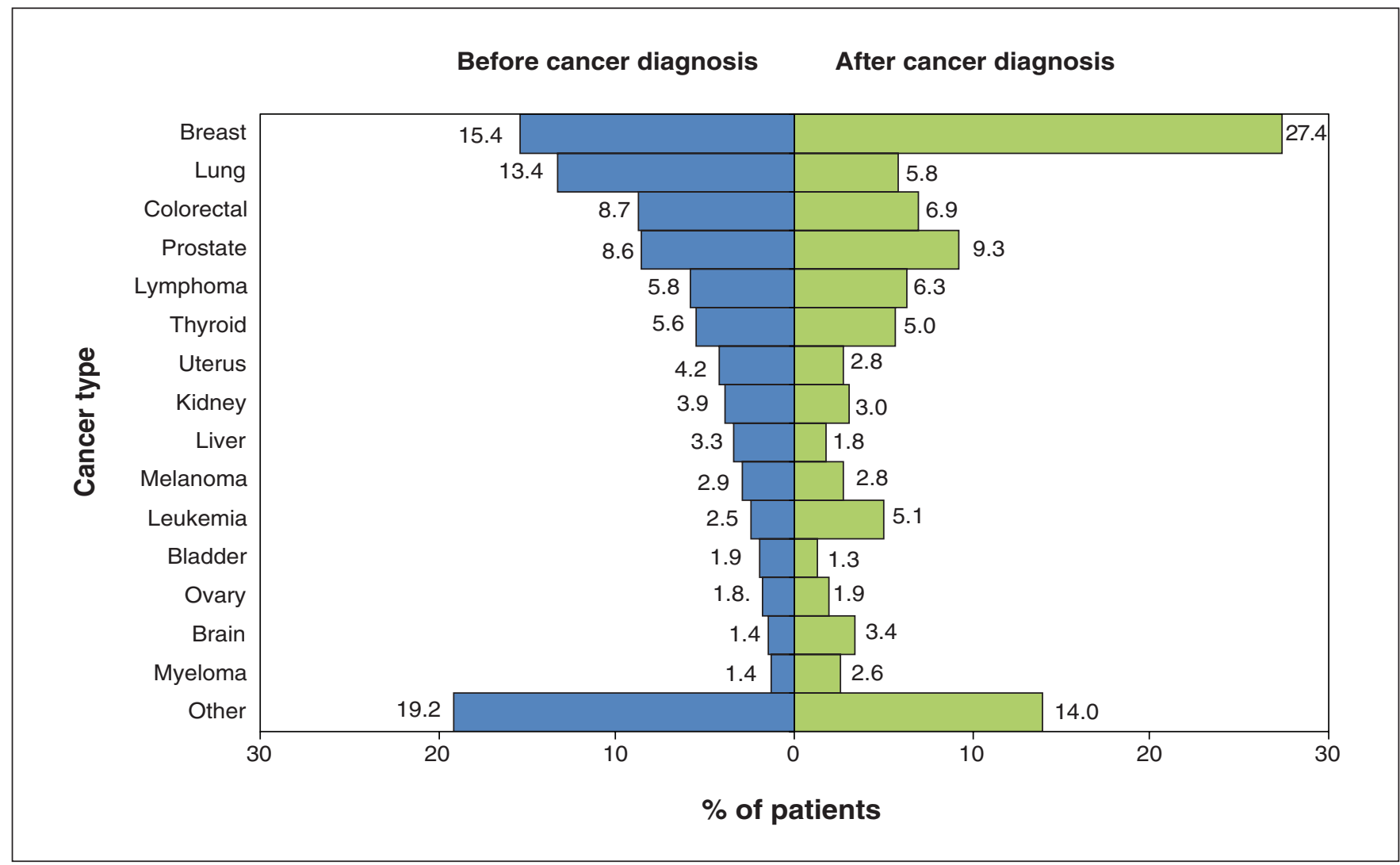

Figure 3: Distribution of cancer type by Trillium Drug Program enrolment before or after cancer diagnosis.

lenalidomide, ruxolitinib and other new drugs increased through to the end of our observation period. Although the vast majority of TDP claims were for noncancer drugs, the amount paid by the program for each cancer treatment drug far exceeded the cost of noncancer drugs.

Not surprisingly, we found that patients who were enrolled in the TDP before their cancer diagnosis had more comorbidities at the time of cancer diagnosis than patients who enrolled after their cancer diagnosis. Thus, they may have had conditions requiring treatment with costly prescription medication, paid for out of pocket, even before their cancer diagnosis. The distribution of cancer diagnoses among patients who were enrolled in the TDP before their diagnosis mirrored the distribution of newly diagnosed cancer cases in the province. ${ }^{33}$ However, among patients who were enrolled in the TDP after their cancer diagnosis, some cancers (breast, thyroid and brain) were overrepresented compared to 2013 Ontario statistics, ${ }^{33}$ whereas others (colorectal and lung) were underrepresented. Although a recent study by de Oliveira and colleagues ${ }^{34}$ showed that many of these cancers did in fact incur the largest financial burden during the first year after cancer diagnosis (about $\$ 480$ million for colorectal cancer, \$450 million for lung cancer, \$270 million for breast cancer and \$240 million for prostate cancer), the drivers of cost varied. Cancers that were overrepresented in our TDP cohort tended to include treatment protocols that would require patients to pay out of pocket for orally administered medications that are costly and/or with long (in some cases lifetime) treatment windows.

The burden of cancer is increasing, as about 1 in 2 Canadians are expected to receive a diagnosis of cancer in their lifetime. ${ }^{35}$ As such, the cost of treating cancer is a major issue, especially within a growing, aging society, where access to increasingly expensive interventions adds to the rising societal costs of cancer care. ${ }^{36,37}$ This is akin to financial toxicity, as rising cancer costs can reduce quality of life owing to severe emotional and family distress, reduce patients' access to care, lead to treatment abandonment and financial bankruptcy, and impede delivery of the highest-quality care. ${ }^{36-38}$ Research has shown that even insured patients with cancer experienced considerable financial burden and altered their care to reduce out-of-pocket costs, such as taking less than the amount of medication prescribed, partially filling prescriptions or opting to not fill prescriptions at all, as well as spending less on food, clothing and leisure activities. ${ }^{39}$ As the number and availability of orally given cancer treatment drugs continue to increase, coupled with patients' preference for oral administration over intravenous administration, cancer treatment may move away from hospital cancer centres, thereby transferring treatment costs more directly to the patient. ${ }^{40-42}$ This can, in turn, exacerbate the issue of financial toxicity for patients in the future as cancer drug prices continue to steadily rise. More needs to be done to make cancer treatment more affordable and equitable for patients. 


\section{Strengths and limitations}

Our rich, comprehensive provincial data allowed us to link population-based samples of patients with cancer to health administrative databases and objectively assess their TDP claims and the costs associated with these claims, as well as objectively determine their cancer diagnosis and drugs dispensed for each patient. Our study also has limitations worth noting. We were not able to access income at the household level and the corresponding TDP deductible incurred by the household. We also lacked information on the indication for drug use, household composition and which person within the household initiated enrolment in the TDP.

\section{Conclusion}

Our results show that cancer treatment drugs are very costly. However, the TDP, available to all Ontarians regardless of their income, can help benefit those with a high financial burden of cancer treatment by substantially offsetting those costs. In fact, TDP recipients are increasingly using the program for high-cost and biologic drugs. As the projected cost of cancer treatment drugs continues to steadily rise with the introduction of novel therapies at higher costs, the TDP is an available resource and support system to aid in managing these debilitating expenditures and prevent the financial toxicity often experienced from a cancer diagnosis. Budget projections may benefit from the consideration of cancer drug claims to obtain a more comprehensive picture of the funding required to sustain this program.

\section{References}

1. A guide to understanding the Trillium Drug Program. Toronto: Ontario Ministry of Health and Long-Term Care; 2013. Available: www.google.ca/url?sa=t\&rct $=\mathrm{j} \& \mathrm{q}=\&$ esrc $=\mathrm{s} \&$ source $=$ web $\& \mathrm{~cd}=3 \& \mathrm{cad}=\mathrm{rja} \&$ uact $=8 \& \mathrm{ved}=0$ ahUKEwizpYmX zvXWAhXr44MKHV5nBJ4QFgg0MAI\&url=http\%3A\%2F\%2Fwww.forms. ssb.gov.on.ca \%2Fmbs\%2Fssb\%2Fforms\%2Fssbforms.nsf\%2FGetFileAttach \%2F014-S46850E-87 15\%2F\%24File\%2F014-S46850E-87.pdf\&usg=AOv Vaw3w-_VYjgf8I8FZiOvFuDG2 (accessed 2019 Jan. 15).

2. De-mystifying the Trillium Drug Program (TDP). North York (ON): Green Shield Canada; 2017. Available: http://assets.greenshield.ca/greenshield/ GSC\%20Stories\%20(BLOG)/Follow\%20the\%20Script/2017/english/Follow \%20the\%20Script_Spring\%202017.pdf (accessed 2019 Jan. 15).

3. 2015/16 report card for the Ontario Drug Benefit Program. Toronto: Ontario Ministry of Health and Long-Term Care; 2016. Available: http://health.gov.on.ca/en/public/ programs/drugs/publications/opdp/docs/odb_report_16.pdf(accessed 2019 Jan. 15).

4. Get help with high prescription drug costs. Toronto: Ministry of Health and Long-Term Care; updated 2019 May 10. Available: www.ontario.ca/page/get -help-high-prescription-drug-costs (accessed 2019 Jan. 15).

5. OPDP at a glance: fiscal year 2016/17 data report. Cat no 026558. Toronto: Ontario Ministry of Health and Long-Term Care; 2018. Available: www. health.gov.on.ca/en/pro/programs/drugs/publications/opdpataglance/docs/ 2016_17_datareport.xlsx (accessed 2019 Jan. 15).

6. Tadrous $M$, Greaves S, Martins D, et al. Catastrophic drug coverage: utilization insights from the Ontario Trillium Drug Program. CMA7 Open 2018;6:E132-8.

7. Office of the Auditor General of Ontario. 2017 annual report. Vol 1 of 2. Toronto: Queen's Printer for Ontario; 2017. Available: www.auditor.on.ca/en/ content/annualreports/arbyyear/ar2017.html\#volume1 (accessed 2019 Jan. 15).

8. Canadian Cancer Action Network; Manitoba Division, Canadian Cancer Sociey. Five-year action plan to address the financial hardship of cancer in Canada: a call for action. Winnipeg: Manitoba Division, Canadian Cancer Society; 2011. Available: www.cancer.ca/ /media/cancer.ca/MB/get\%20involved/take\%20action/financial \%20hardship\%20 of \%20cancer\%20in\%20canada/financialhardshipofcancer-MB -EN.pdf (accessed 2019 Jan. 15).

9. Gordon N, Stemmer SM, Greenberg D, et al. Trajectories of injectable cancer drug costs after launch in the United States. 7 Clin Oncol 2018;36:319-25.

10. de Oliveira C, Bremner KE, Pataky R, et al. Trends in use and cost of initial cancer treatment in Ontario: a population-based descriptive study. CMAf Open 2013;1:E151-8

11. Spencer J, Reeder-Hayes KE, Pinheiro LC, et al. Short and long term impact of financial toxicity on quality of life in the Carolina Breast Cancer study. 7 Clin Oncol 2017;35(Suppl):e18299.
12. Hennessy D, Sanmartin C, Ronksley P, et al. Out-of-pocket spending on drugs and pharmaceutical products and cost-related prescription non-adherence among Canadians with chronic disease. Health Rep 2016;27:3-8.

13. Table 11-10-0222-01: Household spending, Canada, regions and provinces. Ottawa: Statistics Canada; modified 2019 July 11. Available: www5.statcan.gc.ca/ cansim/pick-choisir?lang=eng\&p2=33\&id=2030021 (accessed 2019 Jan. 15).

14. Table 11-10-0227-01: Household spending by age of reference person. Ottawa: Statistics Canada; modified 2019 July 11. Available: www5.statcan.gc.ca/cansim/ pick-choisir?lang=eng\&p2=33\&id=2030026 (accessed 2019 Jan. 15).

15. Kolhatkar A, Cheng L, Morgan SG, et al. Patterns of borrowing to finance out-of-pocket prescription drug costs in Canada: a descriptive analysis. CMA7 Open 2018;6:E544-50.

16. Law MR, Cheng L, Dhalla IA, et al. The effect of cost on adherence to prescription medications in Canada. CMA7 2012;184:297-302.

17. Doshi JA, Li P, Huo H, et al. Association of patient out-of-pocket costs with prescription abandonment and delay in fills of novel oral anticancer agents. 7 Clin Oncol 2018;36:476-82.

18. Specialty drugs: trends, challenges and solutions. Sun Life; 2015. Available: www.sunlife.ca/static/canada/Sponsor/About\%20Group\%20Benefits/Group $\% 20$ benefits \%20products \%20and \%20services/The\%20Conversation/Bright \%20Papers/files/00230-12-15-e.pdf (accessed 2019 Jan. 15).

19. Prescribed drug spending in Canada, 2016: a focus on public drug programs. Ottawa: Canadian Institute for Health Information; 2016. Available: www.google.ca/ url? $\mathrm{sa}=\mathrm{t} \& \mathrm{rct}=\mathrm{j} \& \mathrm{q}=\&$ esrc $=\mathrm{s} \&$ source $=$ web $\& \mathrm{~cd}=5 \& \mathrm{cad}=\mathrm{rja} \& u a c t=8 \& \mathrm{ved}=0 \mathrm{ahUK}$ EwiM0p7-5fXWAhUT24MKHfF8C5oQFghCMAQ\&url=https\%3A\%2F\%2 Fsecure.cihi.ca\%2Ffree_products\%2FPrescribed\%2520Drug\%2520Spending \%2520in\%2520Canada_2016_EN_web.pdf\&usg=AOvVaw1LKeW-MCcE0z O27jgVl1Xd (accessed 2019 Jan. 15).

20. Drivers of prescription drug spending in Canada. Ottawa: Canadian Institute for Health Information; 2012. Available: www.cihi.ca/en/drug_spend_drivers_en. pdf (accessed 2019 Jan. 15).

21. The Johns Hopkins ACG® System version 11.0 technical reference guide. Baltimore: The Johns Hopkins University; 2015.

22. Gershon AS, Wang C, Guan J, et al. Identifying patients with physiciandiagnosed asthma in health administrative databases. Can Respir 7 2009;16:183-8.

23. Schultz SE, Rothwell DM, Chen Z, et al. Identifying cases of congestive heart failure from administrative data: a validation study using primary care patient records. Chronic Dis Inj Can 2013;33:160-6.

24. Tu K, Campbell NR, Chen ZL, et al. Accuracy of administrative databases in identifying patients with hypertension. Open Med 2007;1:e18-26.

25. Hux JE, Ivis F, Flintoft V, et al. Diabetes in Ontario: determination of prevalence and incidence using a validated administrative data algorithm. Diabetes Care 2002;25:512-6.

26. Widdifield J, Bombardier C, Bernatsky S, et al. An administrative data validation study of the accuracy of algorithms for identifying rheumatoid arthritis: the influence of the reference standard on algorithm performance. BMC Musculoskelet Disord 2014;15:216.

27. Benchimol EI, Guttmann A, Mack DR, et al. Validation of international algorithms to identify adults with inflammatory bowel disease in health administrative data from Ontario, Canada. 7 Clin Epidemiol 2014;67:887-96.

28. Table 18-10-0005-01: Consumer Price Index, annual average, not seasonally adjusted. Ottawa: Statistics Canada; modified 2019 July 11. Available: www150. statcan.gc.ca/t1/tbl1/en/tv.action?pid=1810000501 (accessed 2019 Jan. 15).

29. de Oliveira C, Weir S, Rangrej J, et al. The economic burden of cancer care in Canada: a population-based cost study. CMA7 Open 2018;6:E1-10.

30. Aitken M. Global oncology trends 2017: advances, complexity and cost [institute report]. Durham (NC): IQVIA Institute; 2017. Available: www.iqvia.com/ institute/reports/global-oncology-trends-2017-advances-complexity-and-cost (accessed 2019 Jan. 15).

31. Express Scripts Canada ${ }^{\circledR}$ drug trend report 2016. Mississauga (ON): Express Scripts Canada; 2017. Available: www.express-scripts.ca/sites/default/files/ 2016-Drug-Trend-Report.pdf (accessed 2019 Jan. 15).

32. Dusetzina SB. Drug pricing trends for orally administered anticancer medications reimbursed by commercial health plans, 2000-2014. FAMA Oncol 2016;2:960-1.

33. Ontario cancer statistics 2018 [report]. Toronto: Cancer Care Ontario; 2018. Available: www.cancercareontario.ca/sites/ccocancercare/files/assets/OCS2018 _rev13122018.pdf (accessed 2019 Jan. 15).

34. de Oliveira C, Bremner KE, Pataky R, et al. Understanding the costs of cancer care before and after diagnosis for the 21 most common cancers in Ontario: a population-based descriptive study. CMA7 Open 2013;1:E1-8.

35. Nearly 1 in 2 Canadians expected to get cancer: report [media release]. Toronto: Canadian Cancer Society; 2017 June 20. Available: www.cancer.ca/ en/about-us/for-media/media-releases/national/2017/canadian-cancer-statistics/ ?region=on (accessed 2019 Jan. 15).

36. Zafar SY, Abernethy AP. Financial toxicity, Part I: a new name for a growing problem. Oncology (Williston Park) 2013;27:80-1, 149.

37. Zafar SY, Abernethy AP. Financial toxicity, Part II: How can we help with the burden of treatment-related costs? Oncology (Williston Park) 2013;27:253-4, 256.

38. Collins SR, Rasmussen PW, Doty MM, et al. The rise in health care coverage and affordability since health reform took effect: findings from the Commonwealth Fund Biennial Health Insurance Survey, 2014. Issue Brief (Commonw Fund) 2015;2:1-16. 
39. Zafar SY, Peppercorn JM, Schrag D, et al. The financial toxicity of cancer treatment: a pilot study assessing out-of-pocket expenses and the insured cancer patient's experience. Oncologist 2013;18:381-90.

40. Aisner J. Overview of the changing paradigm in cancer treatment: oral chemotherapy. Am 7 Health Syst Pharm 2007;64(Suppl 5):S4-7.

41. Weingart SN, Brown E, Bach PB, et al. NCCN task force report: oral chemotherapy. 7 Natl Compr Canc Netw 2008;6(Suppl 3):S1-14.

42. Eek D, Krohe M, Mazar I, et al. Patient-reported preferences for oral versus intravenous administration for the treatment of cancer: a review of the literature. Patient Prefer Adherence 2016;10:1609-21.

Affiliations: ICES (Cheng, Saxena, Earle); Sunnybrook Research Institute (Seung, Mittmann) and Odette Cancer Centre (Earle, Chan), Sunnybrook Health Sciences Centre; Departments of Medicine (Earle, Chan) and Pharmacology and Toxicology (Mittmann), University of Toronto; Canadian Centre for Applied Research in Cancer Control (Chan); Canadian Partnership Against Cancer (Earle), Toronto, Ont.

Contributors: Stephanie Cheng analyzed the data. Stephanie Cheng and Farah Saxena drafted the manuscript, and Soo Seung, Craig Earle, Kelvin Chan and Nicole Mittmann revised it critically for important intellectual content. All of the authors contributed significantly to study conceptualization and design, and data interpretation, approved the final version to be published and agreed to act as guarantors of the work.
Funding: This study was supported by ICES, which is funded by an annual grant from the Ontario Ministry of Health and Long-Term Care, and by a grant from the Health Services Research unit of the Ontario Institute for Cancer Research.

Acknowledgements: The authors thank IMS Brogan Inc. for use of their Drug Information Database. They acknowledge Carlo De Angelis for his clinical contribution to this work.

Disclaimer: The opinions, results and conclusions reported in this paper are those of the authors and are independent from the funding sources. No endorsement by ICES or the Ontario Ministry of Health and LongTerm Care is intended or should be inferred. Parts of this material are based on data and information provided by Cancer Care Ontario (CCO). The opinions, results, views and conclusions reported in this paper are those of the authors and do not necessarily reflect those of CCO. No endorsement by CCO is intended or should be inferred. Parts of this material are based on data and/or information compiled and provided by the Canadian Institute for Health Information (CIHI). However, the analyses, conclusions, opinions and statements expressed in the material are those of the authors and not necessarily those of CIHI.

Supplemental information: For reviewer comments and the original submission of this manuscript, please see www.cmajopen.ca/content/7/3/ E516/suppl/DC1. 